\title{
ELECTROMAGNETIC AIR COMPRESSOR FOR GAS TURBINE APPLICATIONS
}

\author{
AKSHAY SHINDE ${ }^{1} \&$ YASH PAL $^{2}$ \\ ${ }^{1}$ M.Tech Scholar, School of Aeronautical Sciences, Hindustan Institute of Technology and Science, Chennai, India \\ ${ }^{2}$ Associate Professor, School of Aeronautical Sciences, Hindustan Institute of Technology and Science, Chennai, India
}

\begin{abstract}
In the process of improving the performance of a normal turbofan engine to meet the new European norms, a German company Bauhaus Luftfahrt is developing a new generation of engines which is a hybrid of piston and jet engine. In this prototype engine, the high-pressure compressor stages are replaced with a 3-piston system where each consists of 12 cylinders in total 8 for compression and 4 for combustion. This piston system enables the engine to achieve hectopressure ratio and thus improving the performance of the engine. These 3 piston systems are mounted along the circumference of the main shaft of the engine, this indirectly increases the weight of the engine. As there isnumber of stages in the piston system to transmit the energy from one stage to another a mechanical linkage such as a crankshaft is required which is one of the heaviest components in the assembly of the compression system. In aircraft design reducing the weight of the components is a key consideration, hence any method of reducing the weight of the piston system will improve the efficiency of the entire system. While researching solutions for this problem, possibly a new method of air compression was discovered by utilizing the electromagnetic force generated by copper coils. Based on this basic principle, a new system of air compression is being developed which uses electromagnetic force from coils rather than the mechanical force from a motor to compress the air for a system. As this is a new concept the designing had to be done from a top to bottom approach considering the output is fixed at $0.2 \mathrm{MPa}$ pressure. For the design, a double-acting cylinder was considered as it increases the output volume for the same dimensions as a normal piston air compressor.
\end{abstract}

KEYWORDS: Hectopressure Ratio, Electromagnetic, Air Compressor \& Gas Turbine

Received: Jun 06, 2020; Accepted: Jun 26, 2020; Published: Jul 28, 2020; Paper Id.: IJMPERDJUN2020496

\section{INTRODUCTION}

Theaviation field is always searching for new developments in aircraft so that they can be more efficient in the transportation of goods and persons. The future norms established by the European Commission for the aviation sector demand the aircraft be more efficient and reduce pollution(Group, n.d.). To meet these new standards Bauhaus Luftfahrt a German-based research institute is developing a new engine known as the Composite Cycle Engine (CCE)(Kaiser, Kellermann, Nickl, \& Seitz, 2018). This engine is a hybrid of a piston and a turbo fan engine. In this new engine, the High-Pressure Compressor (HPC) portion of the normal turbofan engine is replaced with a piston system. This piston system consists of 12 stages each out of which 8 are for compression and 4 are for combustion in that order, there istotal 3 such piston system per engine(Nickl, V, Kaiser, \& V, 2017).This piston system enables the engine to achieve a heat pressure ratio due to close volume compression. The major drawback of this piston system is the crankshaft which is used to connect the stages of the compressor to transmit power. As there are 3 such piston systems there is a significant increase in weight due to the crankshaft. To overcome this limitation, this paper discusses a new type of air compression system which uses electromagnetic force instead of 
mechanical linkage to transmit power from one stage to another. In this new concept, there are coils which develop magnetic flux which attracts the piston and compression takes place.(Lee, Kim, \& Kim, 2016)(Cravey, Devlin, Loree, Strohl, \& Young, n.d.)(Zhang, Ruan, Hu, \& Liu, 2012) This paper explains the design and manufacturing of the prototype model for the electromagnetic compressor. The constant element while designing the electromagnetic air compressor was the stroke which was fixed at $150 \mathrm{~mm}$ as per the stroke in the piston system.

\section{MATERIAL AND METHODS}

Theimportant factor while selecting material for the prototype was the magnetic properties of a material. As the concept uses electromagnetic forces to do the work and provide the energy for compression, the part which will provide the motion will have to be made of ferrous material. The rest of the arrangement can be made of lightweight material to further aid in reducing the weight. The coils need to be made of copper as it is a good conductor. While design, manufacturing of every part of the system would not be optimum, but the most important aspect of the design is safety. A cylinder of required dimensions has to be made to provide the necessary volume for compression. The cylinder also is required to be easily disassembled so that any maintenance or inspection work can be carried out. The piston should have extended rods on both the side at a length greater than 1.6 times the stroke of the piston. As most of the components are circular in nature most of the operations can be achieved on a lathe machine. The cylinder and piston which are the main components were made on the lathe machine by selecting two solid rods of 60 and $40 \mathrm{~mm}$ of the cylinder and piston respectively. Then these rods were machined according to the design on a manual lathe. For the ports for the inlet and outlet vertical drill machine was used and the tap was selected on bases of the T-section which was to be attached.

\section{DETAILED DESIGN}

The first consideration while designing the electromagnetic air compressor is that the prototype will be a double-acting cylinder which will double the volume output per cycle which increases the efficiency. This enables to compress air both in forward and reverse stroke which utilizes the energy more efficiently. One of the factors for design is the stroke which is already determined to be $150 \mathrm{~mm}$ according to which the diameter of the piston is determined. To calculate the diameter of the piston the Boyle's Law equation is used.

$$
\mathrm{P}_{1} \mathrm{~V}_{1}=\mathrm{P}_{2} \mathrm{~V}_{2}
$$

Were,

$\mathrm{P}_{1}$ is the pressure of atmospheric air. $(0.1013 \mathrm{MPa})$

$\mathrm{V}_{1}$ is the maximum volume available in the cylinder.

$\mathrm{P}_{2}$ is the required output pressure. $(0.2 \mathrm{MPa})$

$\mathrm{V}_{2}$ is the volume remaining after compression.

By using this equation, we can determine the diameter of the cylinder to achieve the required pressure. The maximum volume will be achieved at the maximum stroke that is $150 \mathrm{~mm}$ and the minimum volume will be at the clearance volume. One more factor which determines the volume inside the cylinder are the rods which extruded from both the side of the piston. These rods occupy some volume inside the cylinder which has to be considered while selecting the diameter of the piston. The intake pressure is $1 \mathrm{~atm}$ and the desired output pressure is $2 \mathrm{MPa}$, so by substituting the values 
in the equation, we calculated the piston diameter to be $32 \mathrm{~mm}$. After calculating the piston diameter, the rod diameter was selected to be $12 \mathrm{~mm}$ to get the required volume for compressionInitially the design of the cylinder was one solid block, but later it was identified that for maintenance and inspection purpose the cylinder needed to have some kind change in design so that it could be opened and the inner surface could be inspected. To achieve this the cylinder was split into two parts, male and female. The male section had external threading and the female section had internal threading. They would align properly so that after the parts are screwed over each other they would form one seamless chamber for the piston.As it is a double-acting cylinder there should be a separation between the two sections. The piston is the dividing factor between the two chambers and to make the chambers leakproof 2 O-rings were placed over the piston.After the manufacturing of the cylinder and the piston, a base has to be made for fixing and damping the cylinder. As the coils will exert force on the rod's momentum will be created and due to that momentum vibrations will be created. To reduce these vibrations and to hold the cylinder in one place steadily a wooden fixture is to be made which can house the cylinder so that the motion parallel to the axis of the rods is minimized. To ensure that the cylinder remains in place a locking mechanism to hold the cylinder is to be designed.The cylinder is divided into three sections, each of $59 \mathrm{~mm}$ one section is common to both the male and female sections which havethe threading.

\section{MALE CYLINDER}

The male cylinder with a total length of $118 \mathrm{~mm}$ and $44 \mathrm{~mm}$ external diameter. This cylinder was made from a solid rod of $60 \mathrm{~mm}$ diameter and then was machined on a lathe machine to the required dimensions. The internal diameter was ground after machining so rust formation is prevented as a smooth surface is created.

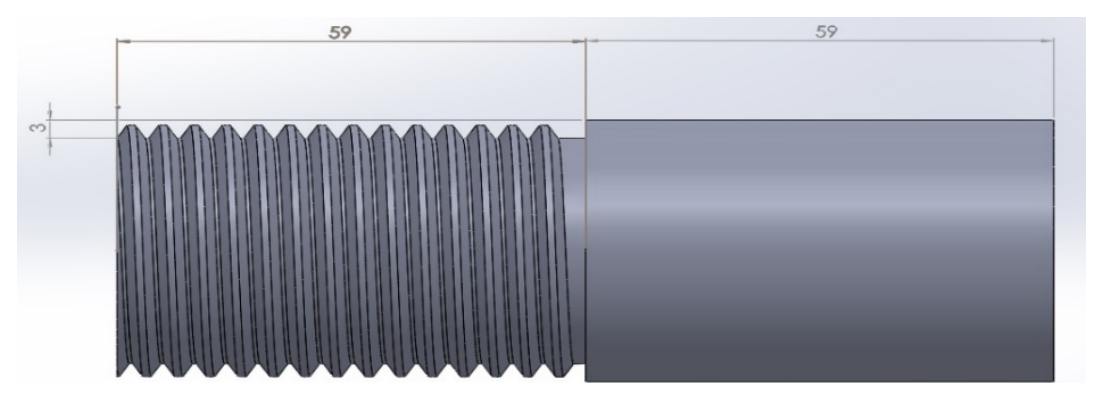

Figure 1: Side View of Male Cylinder

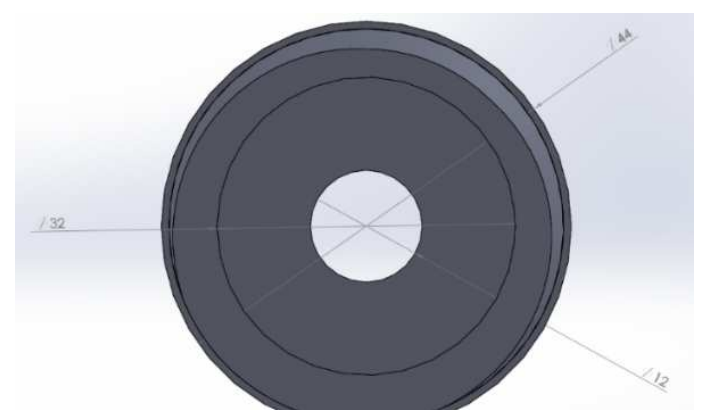

Figure 2: Front view of Male Cylinder

\section{FEMALE CYLINDER}

The only major difference is that the male cylinder has external threading and the female cylinder has internal threading. The female cylinder is also divided into three sections of $59 \mathrm{~mm}$ each. The internal diameter is as the male cylinder so that after the cylinders are combined they form what seems likeone single cylinder without any obstruction to the path of the 
piston.

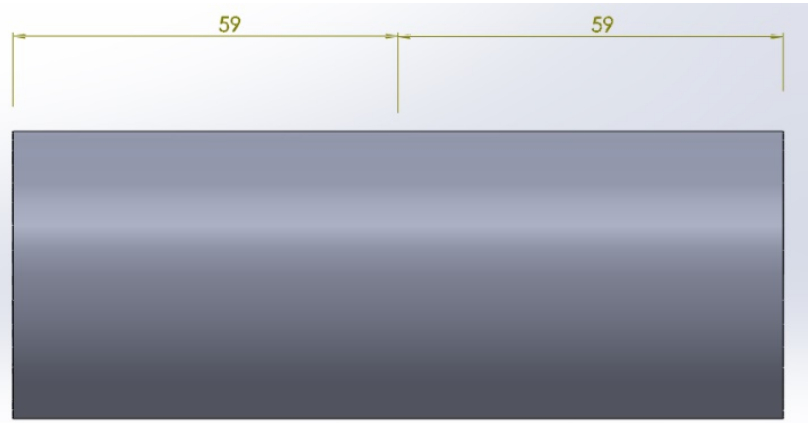

Figure 3: Side View of Female Cylinder

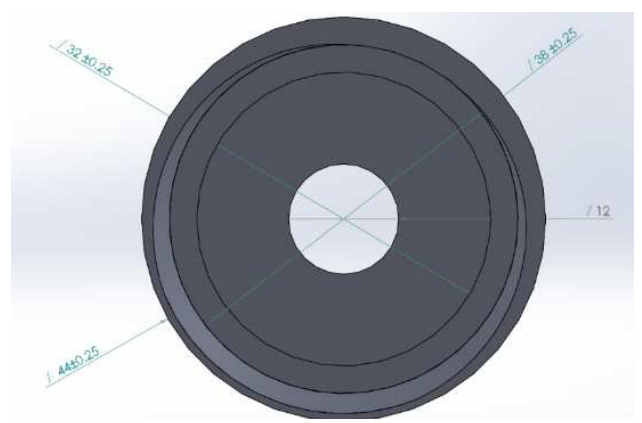

Figure 4: Front View of Female Cylinder

\section{CYLINDER ASSEMBLY}

This is the completely assembled cylinder when the male and Female cylinders are completely screwed over each other. After that, the common section on which the threading is provided is completely sealed off and the two cylinders form one single unit. The internal surface is also completely aligned so that the piston can move in a fluid motion.Before closing the cylinder, the total length is $236 \mathrm{~mm}$ and after closing as one section of $59 \mathrm{~mm}$ is common to both the cylinders the total length of the closed cylinder is $177 \mathrm{~mm}$. In building the prototype the same material was selected for manufacturing both the piston \& Rod and the cylinder, but it is not necessary that the cylinder material be ferrous. We can even select a nonferrous material for the cylinder as the cylinder doesn't need to react to the magnetic flux generated by the coils. The cylinder can also be made from a composite material which will make the assembly even lighter which can further improve the efficiency of the compressor.

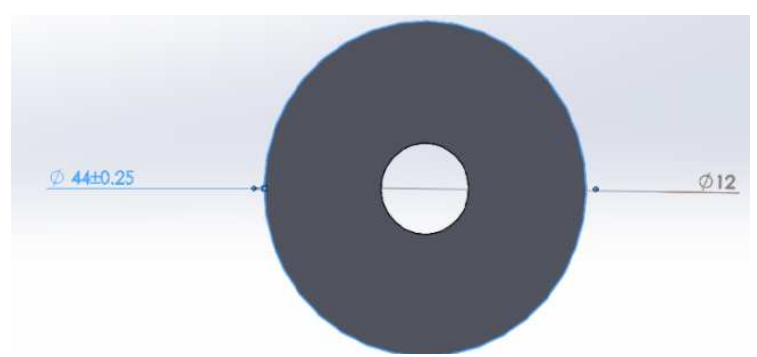

Figure 5: Side View of Assembled Cylinder. 


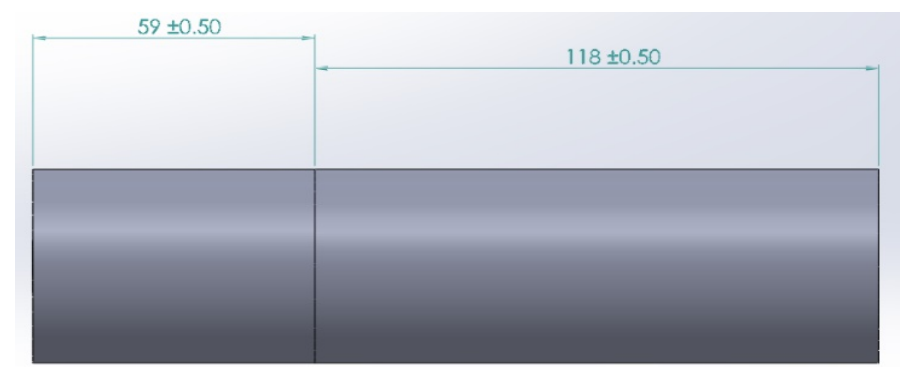

Figure 6: Side View of Closed Cylinder Assembly

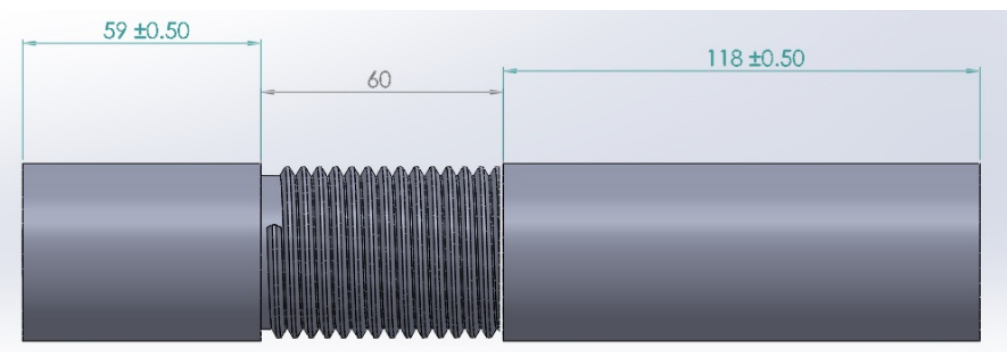

Figure 7: Side View of Open Cylinder assembly

\section{PISTON AND ROD}

The diameter of the piston is the inner diameter of the cylinder so asit should be a tight fit so that there is no air leakage between the two chambers. The length of the rods is greater so that the coils can have a surface area to work over. The length of the rods is 1.6 times the stroke. The piston \& rods are made from one solid rod of $40 \mathrm{~mm}$ diameter.

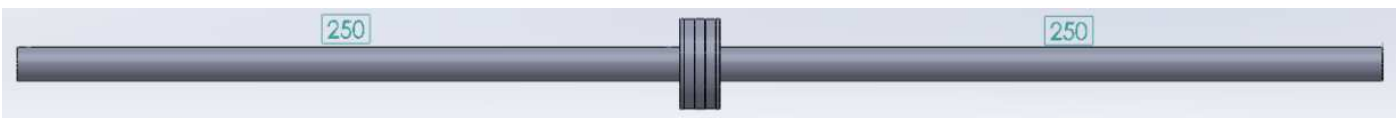

Figure 8: Side View of Piston and Rods

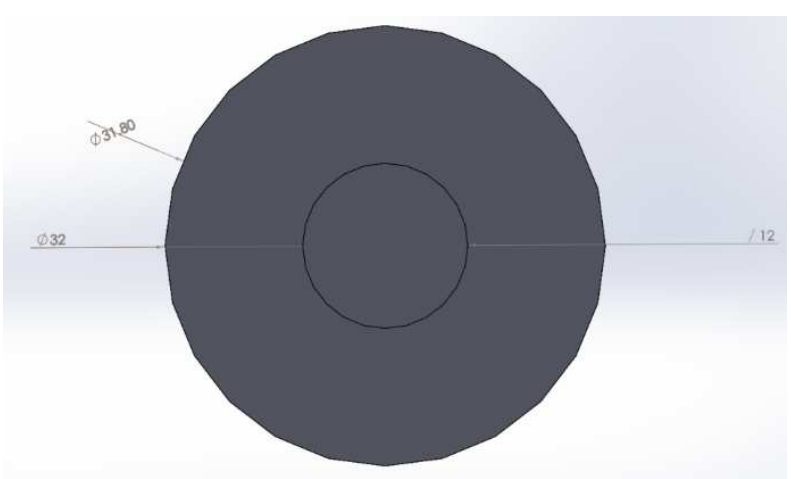

figure 9:Front View of Piston \& Rods

One important element while designing the piston are the O-rings which will prevent the flow of air between both the chambers. 2 O-rings are used with $4 \mathrm{X} 4$ square cross-section which was custom made for the piston and due to this the total thickness of the piston is increased. 


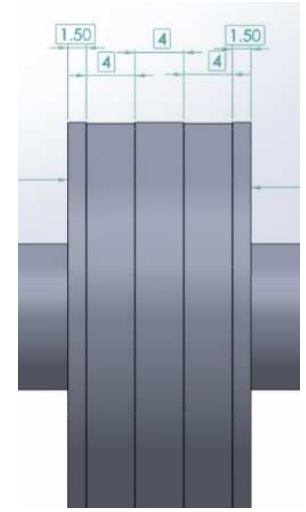

Figure 10: Side View of Piston

\section{RESULTS AND DISCUSSIONS}

There are two major components in the project the cylinder and the piston. There istwo kinds of external forces acting on these components, the pressure inside the cylinder and axial load on the piston. The components have to be tested for failure under these conditions. The desired output pressure is $0.2 \mathrm{MPa}$ but we have done an analysis of up to $1.2 \mathrm{MPa}$ for future modifications. Three properties are measured in every analysis deformation, stress, and strain and the varying factor is the pressure and corresponding force applied. To calculate the force applied the area considered is of the rod of $12 \mathrm{~mm}$ diameter.

\section{CYLINDER ANALYSIS}

As seenin the design the cylinder is split into two half male and female for the convenience of maintenance, but the analysis is done on the component as an assembled unit. The analysis was done to know the three main factors like deformation, stress, and strain. The cylinder has been given cylindrical support over the entire curved surface and fixed support from both the side. Then for the pressure applied the internal surfaces of the cylinder have been selected. The pressure is being varied from $0.2,0.3,0.5,0.7,0.9$ and $1.2 \mathrm{MPa}$. The desired output is only $0.2 \mathrm{MPa}$ but for safety purpose, higher pressures output analysis was also done.

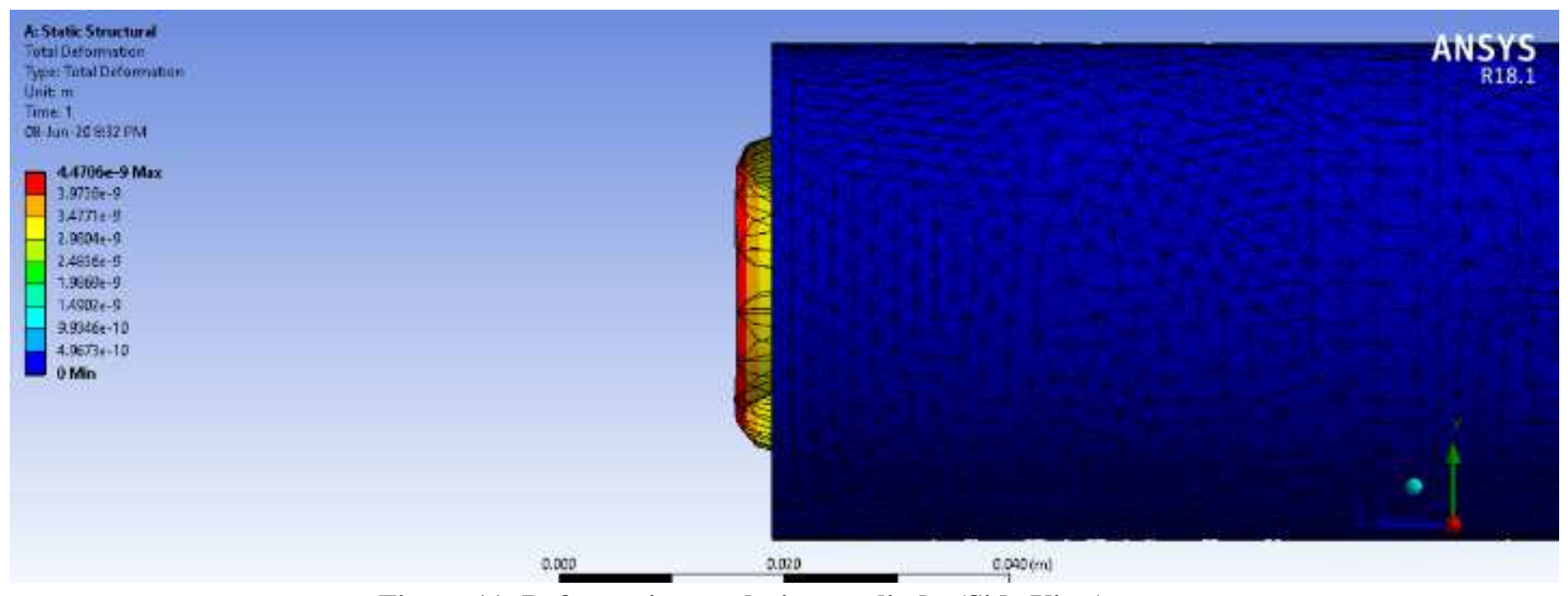

Figure 11: Deformation analysis on cylinder(Side View) 

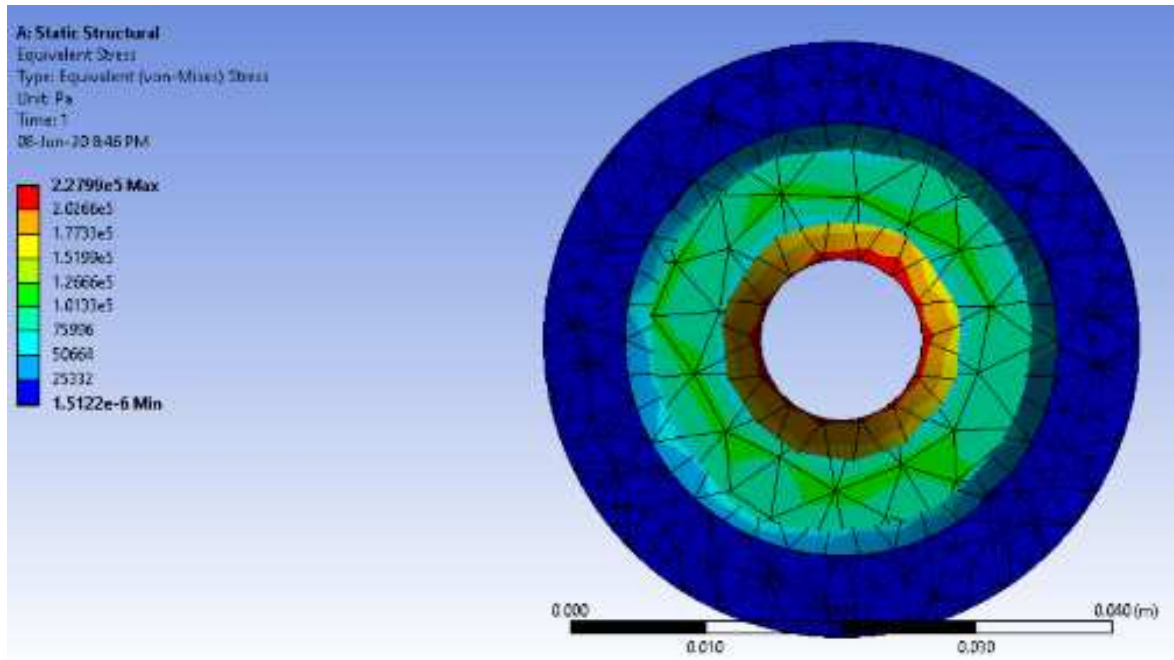

ANSYS

Figure 12: Stress analysis on piston (Cut View)
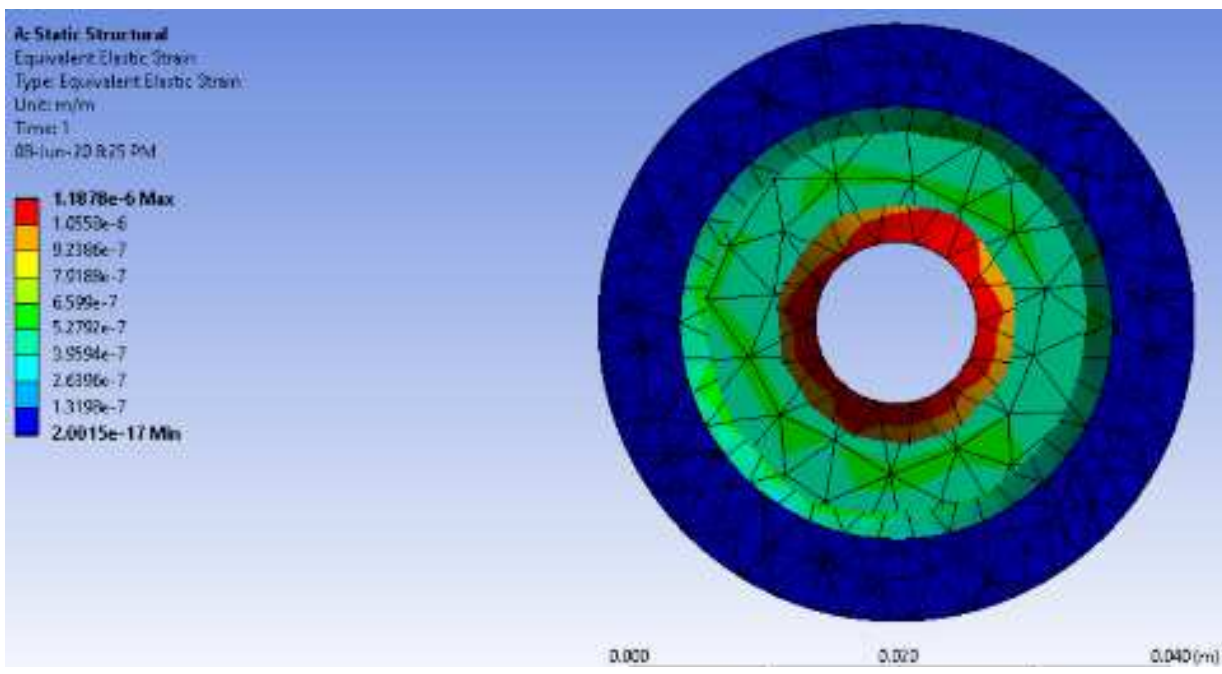

Figure 13: Strain Analysis on Cylinder (Cut Section)

Table 1: Structural Analysis of Cylinder

\begin{tabular}{|c|c|c|c|c|c|c|}
\hline Pressure (MPa) & \multicolumn{2}{|c|}{ Deformation $(\mathbf{m m})$} & \multicolumn{2}{c|}{ Stress (MPa) } & \multicolumn{2}{c|}{ Strain } \\
\hline & Min & Max & Min & Max & Min & Max \\
\hline 0.2 & 0 & $4.47 \mathrm{E}-06$ & $1.51 \mathrm{E}-12$ & 0.22799 & $2.00 \mathrm{E}-17$ & $1.19 \mathrm{E}-06$ \\
\hline 0.3 & 0 & $6.71 \mathrm{E}-06$ & $1.46 \mathrm{E}-12$ & 0.34198 & $2.06 \mathrm{E}-17$ & $1.78 \mathrm{E}-06$ \\
\hline 0.5 & 0 & $1.12 \mathrm{E}-05$ & $1.53 \mathrm{E}-12$ & 0.56997 & $2.13 \mathrm{E}-17$ & $2.97 \mathrm{E}-06$ \\
\hline 0.7 & 0 & $1.56 \mathrm{E}-05$ & $1.88 \mathrm{E}-12$ & 0.79796 & $2.14 \mathrm{E}-17$ & $4.16 \mathrm{E}-06$ \\
\hline 0.9 & 0 & $2.01 \mathrm{E}-05$ & $2.07 \mathrm{E}-12$ & 1.026 & $2.15 \mathrm{E}-17$ & $5.35 \mathrm{E}-06$ \\
\hline 1.2 & 0 & $2.68 \mathrm{E}-05$ & $2.10 \mathrm{E}-12$ & 1.3679 & $2.19 \mathrm{E}-17$ & $7.13 \mathrm{E}-06$ \\
\hline
\end{tabular}




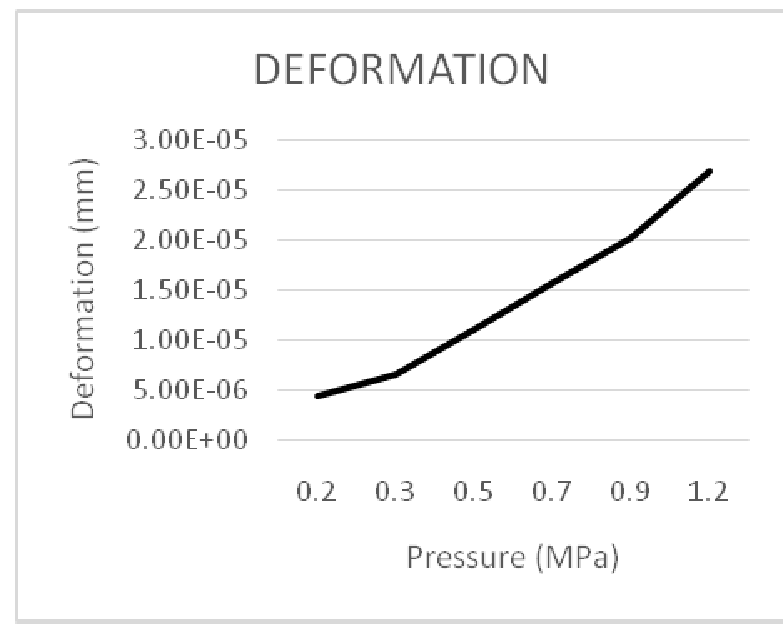

(a)

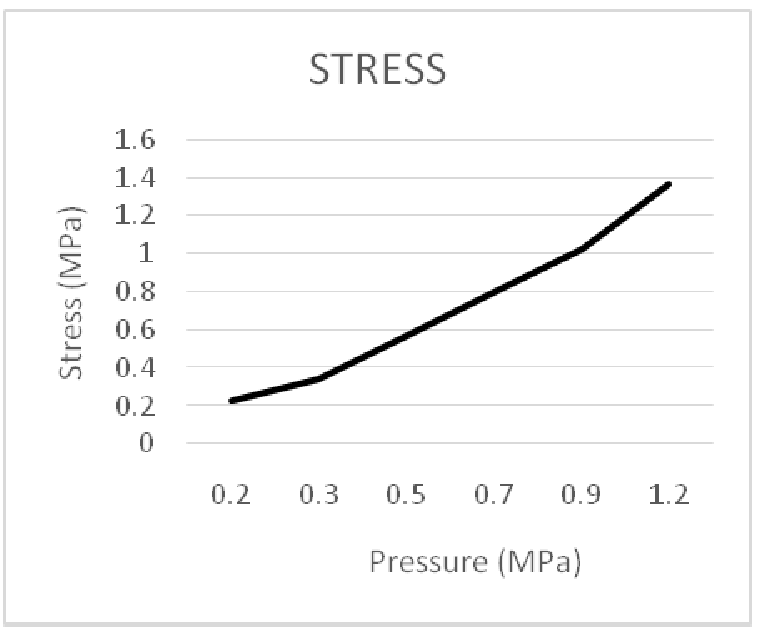

(b)

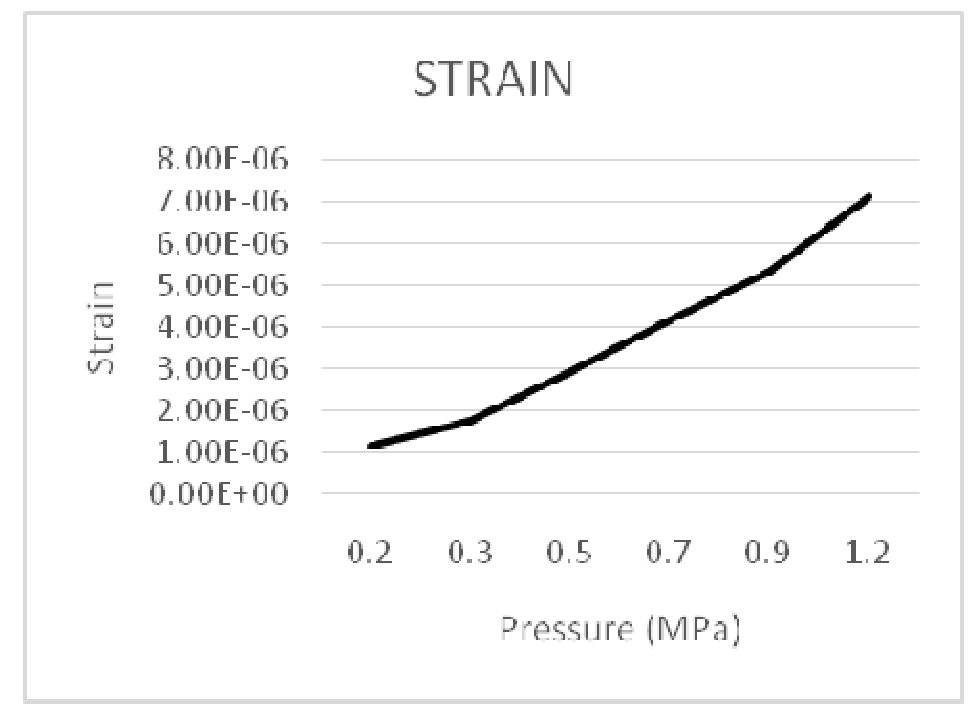

(c)

Figure 14: (a) Pressure V/S Deformation (b)Pressure V/S Stress (c)Pressure V/S Strain for cylinder

\section{PISTON AND RODS ANALYSIS}

The piston design includes the rods on both sides and the piston is provided with grooves for two O-rings so that the chambers are sealed and the air doesn't leak and there is no pressure loss. T who forces are acting on the piston, a force thatwill be exerted on both the rods by the coils and the pressure which acts on the surface of the piston from both sides. The piston has been given cylindrical support to mimic the inner surface of the cylinder. The frictional force on the piston is not considered and only external forces are considered. 


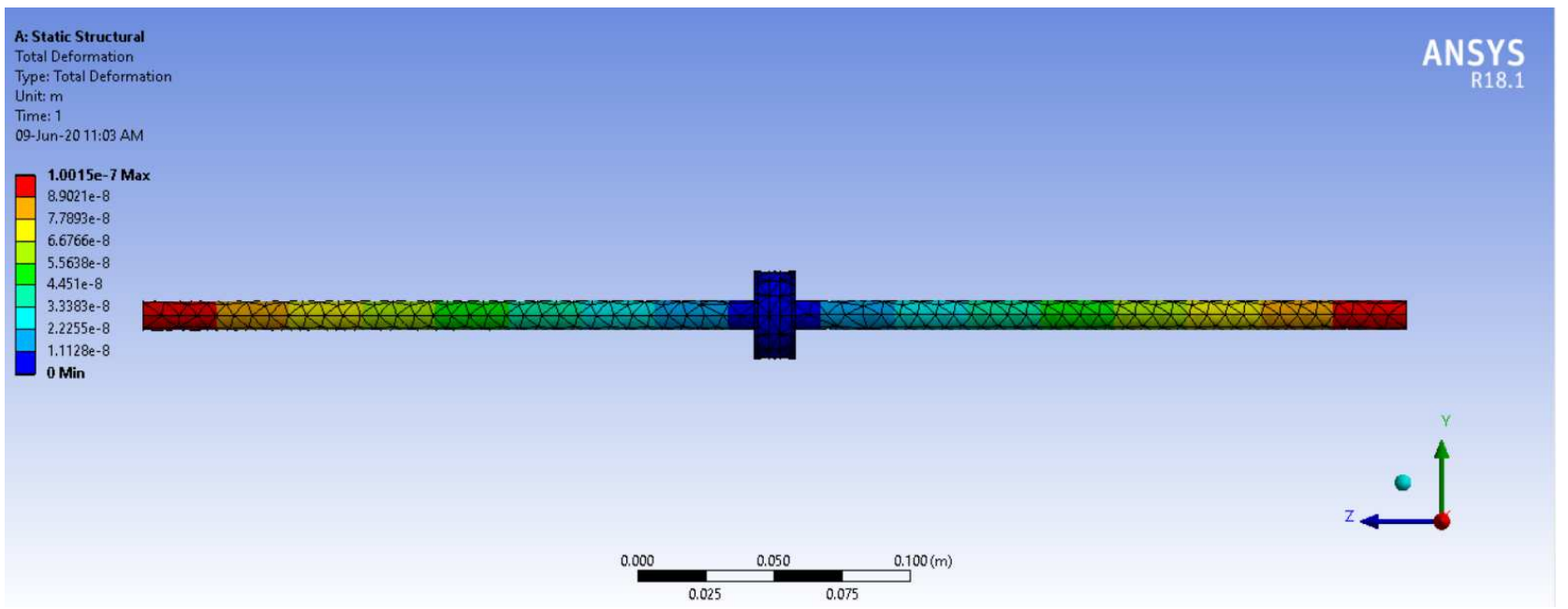

Figure 15: Deformation analysis on Piston and Rods

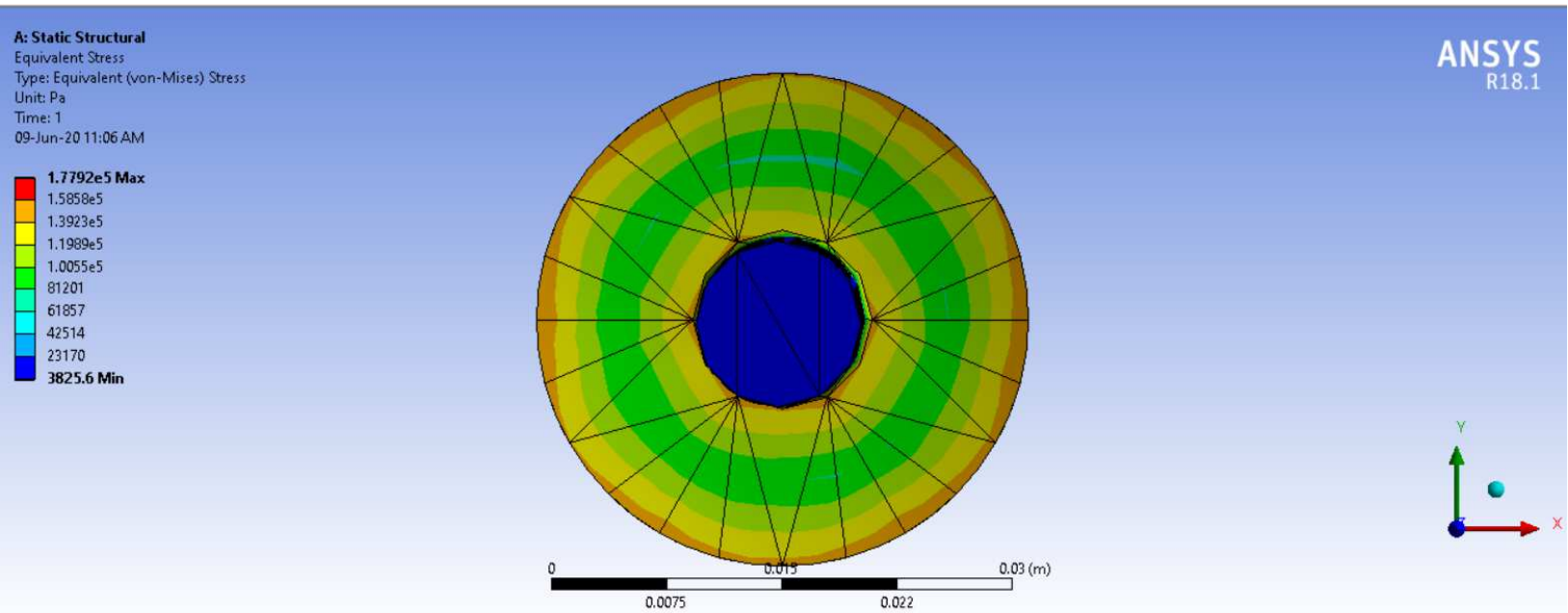

Figure 16: Stress analysis on Piston and Rods

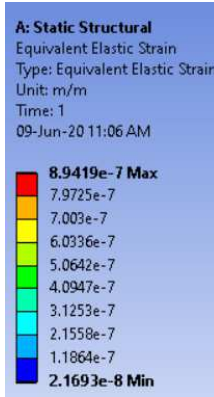

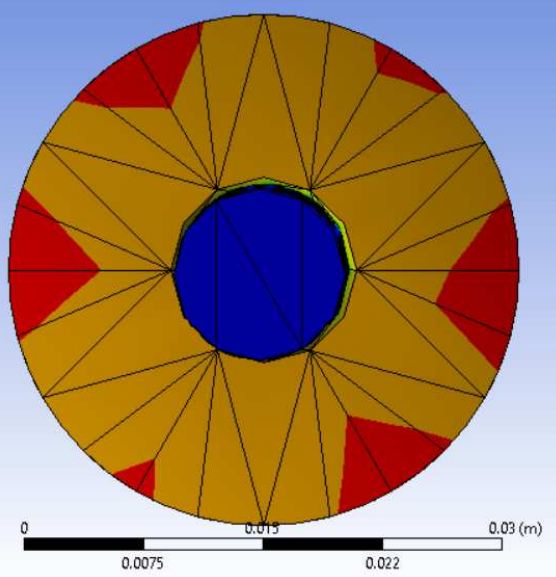

ANSYS

Figure 17: Strain analysis on Piston and Rods 
Table 2: Structural Analysis of Piston

\begin{tabular}{|c|c|c|c|c|c|c|c|}
\hline \multicolumn{2}{|c|}{ Pressure (MPa) } & Force (N) & \multicolumn{2}{c|}{ Deformation (mm) } & \multicolumn{2}{c|}{ Strain } & \multicolumn{2}{c|}{ Stress (MPa) } \\
\hline \multicolumn{2}{|c|}{} & Min & Max & Min & Max & Min & Max \\
\hline 0.2 & 22 & 0 & 0.00010015 & $2.17 \mathrm{E}-08$ & $8.94 \mathrm{E}-07$ & 0.0038256 & 0.17792 \\
\hline 0.3 & 33 & 0 & 0.00015022 & $3.25 \mathrm{E}-08$ & $1.34 \mathrm{E}-06$ & 0.0057384 & 0.26688 \\
\hline 0.5 & 55 & 0 & 0.00025037 & $5.42 \mathrm{E}-08$ & $2.24 \mathrm{E}-06$ & 0.009564 & 0.4448 \\
\hline 0.7 & 77 & 0 & 0.00035052 & $7.59 \mathrm{E}-08$ & $3.13 \mathrm{E}-06$ & 0.01339 & 0.62272 \\
\hline 0.9 & 99 & 0 & 0.00045067 & $9.76 \mathrm{E}-08$ & $4.02 \mathrm{E}-06$ & 0.017215 & 0.80065 \\
\hline 1.2 & 132 & 0 & 0.00060089 & $1.30 \mathrm{E}-07$ & $5.37 \mathrm{E}-06$ & 0.022954 & 1.0675 \\
\hline
\end{tabular}

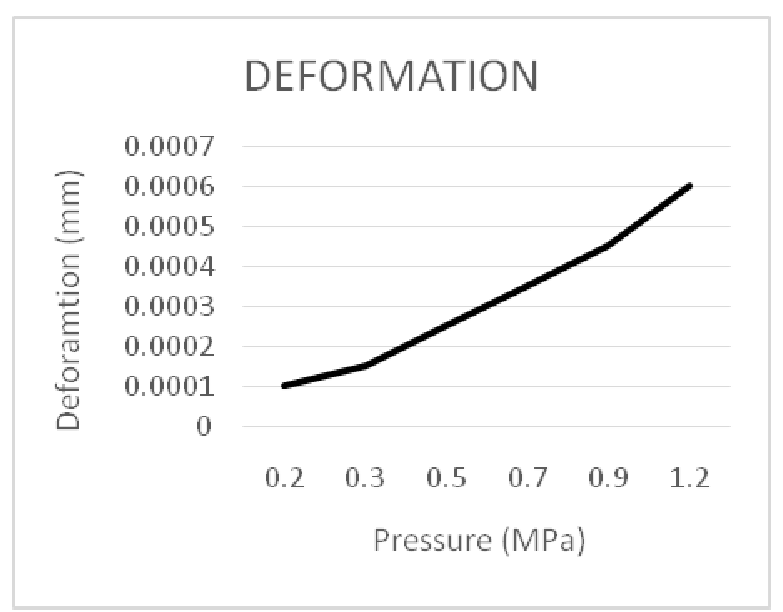

(a)

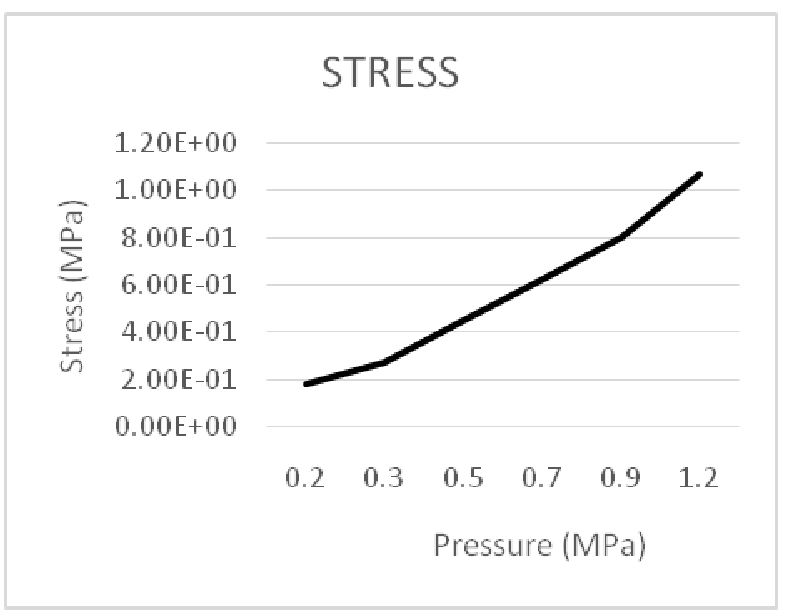

(b)

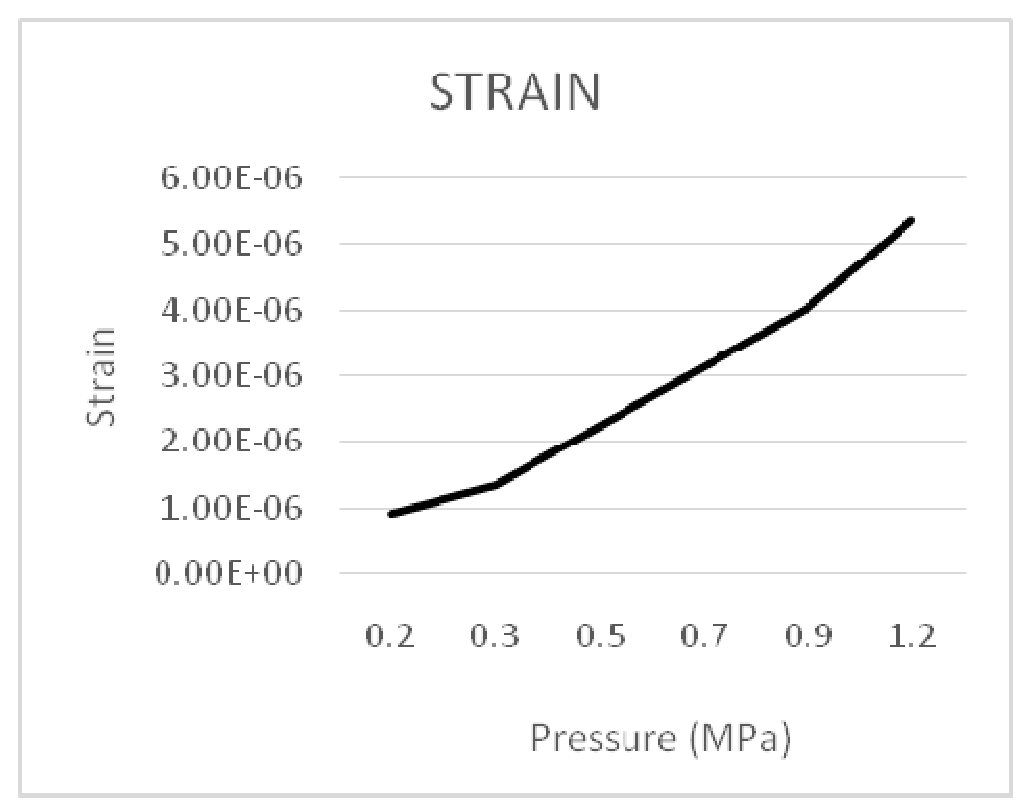

(c)

Figure 15: (a) Pressure V/S Deformation (b)Pressure V/S Stress (c)Pressure V/S Strain for piston 


\section{PROTOTYPE}

The material for the components is also selected which is EN31. This material was selected due to its easily machinability property and strength. This material is also cheap and readily available. The only part remaining is to give the design to a manufacturer and make the prototype. The machining was done and the prototype was ready the only mechanical aspect remaining was the holes for the ports. The sizing of the ports was decided based on the sizing of the fittings which were all $1 / 4$ of an inch and the tube size was $6 \mathrm{~mm}$. The various pneumatic components are shown in Fig. 16. The threaded T-Section decided the size of the hole and the tapping size so that they can be attached to the cylinder. The flow control valves are there to control the volume of inward air so that the desired output pressure is achieved. The remaining T-Sections are to direct the pressurized air towards the pressure sensor as shown in Fig. 17.

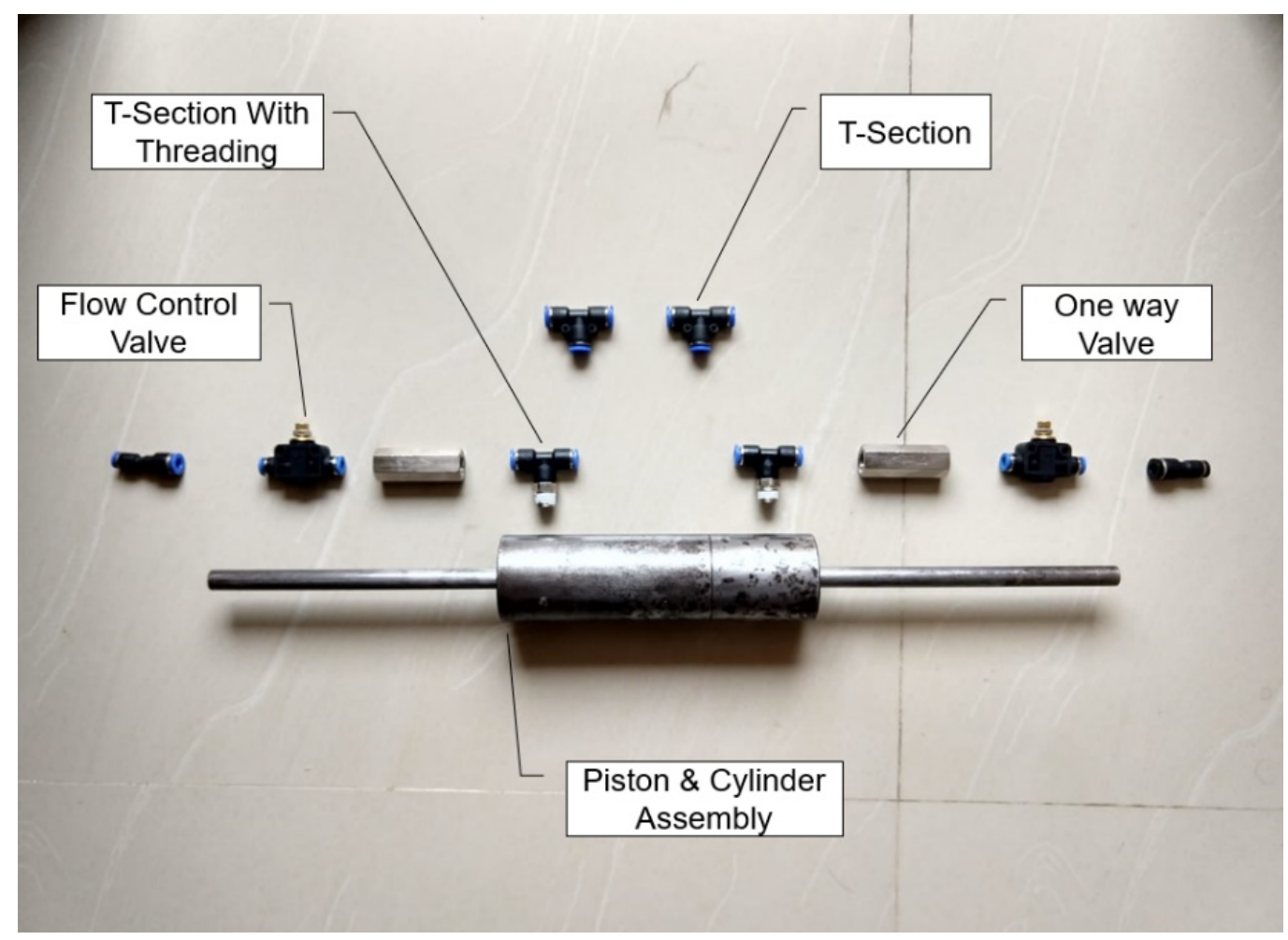

Figure 16: Components of the prototype

Fig. 17 show the flow of the intake air, pressurized air, and exhaust air. Indicated in the blue arrows arethe intake air the first components it passes through is the flow control valve to determine the volume of intake air, the second component is the one-way direction control valve which does not allow the intake air to flow back out of the system. It also severs as a block for the pressurized air so that it does not leave the system and goes towards the pressure sensor. To allow the pressurized air to go towards the pressor sensor there is a manually operated valve so that we can allow the air to reach its maximum pressure. 


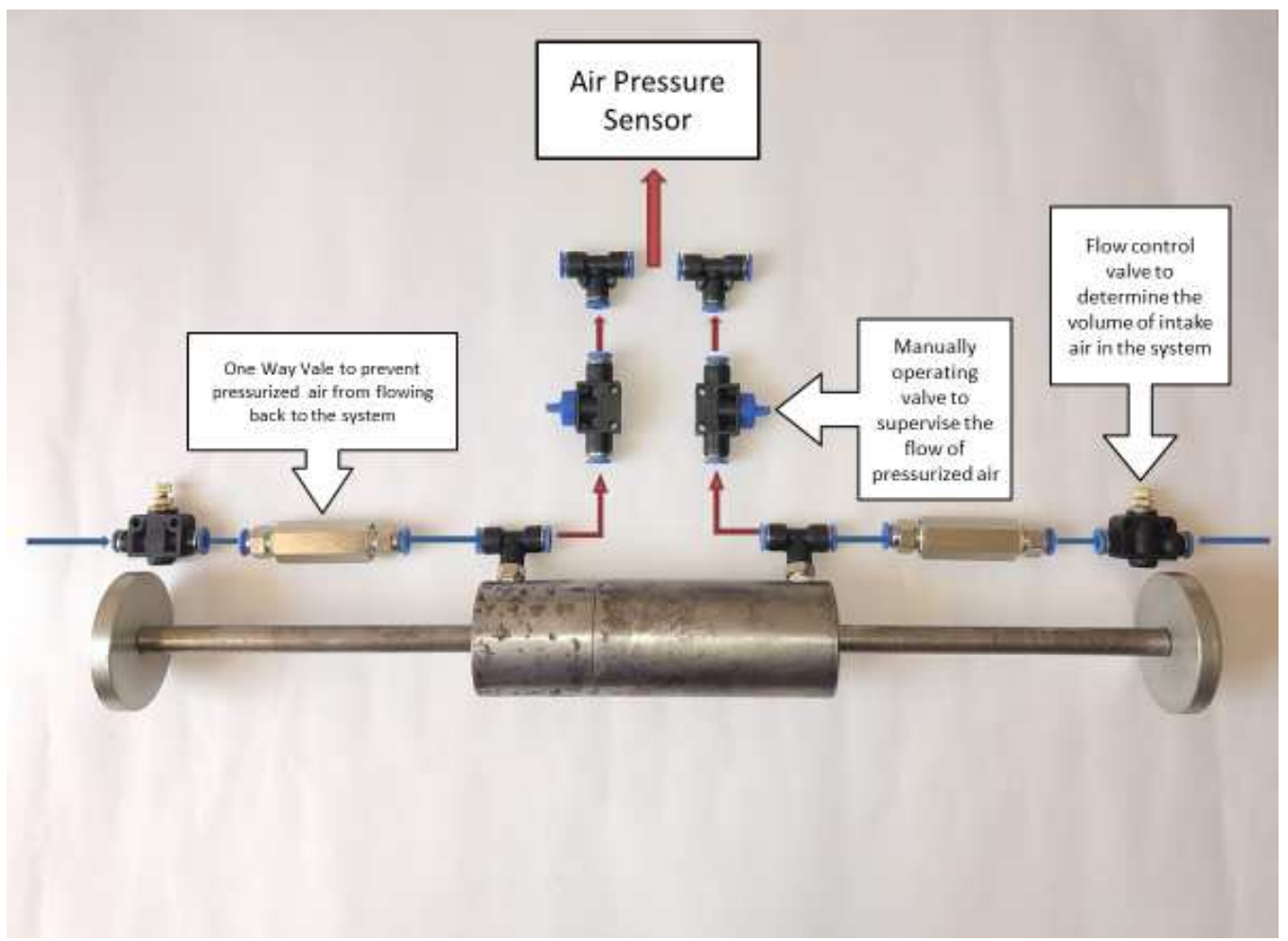

Figure 17: Flow pattern of air through the system

After the basic construction of the cylinder and pneumatic system, a fixture/base is required to mount all the parts. For this, we have taken a wooden ply piece to fix all the components and for the cylinder a solid wooden block with grooves to fit the cylinder in it. The wooden block is screwed to the plywood. The second part of the fixture is the coil arrangement which consists of two wooden I shaped bases on which the coils will be wounded. These two fixtures for the coils are placed on both sides of the cylinder.

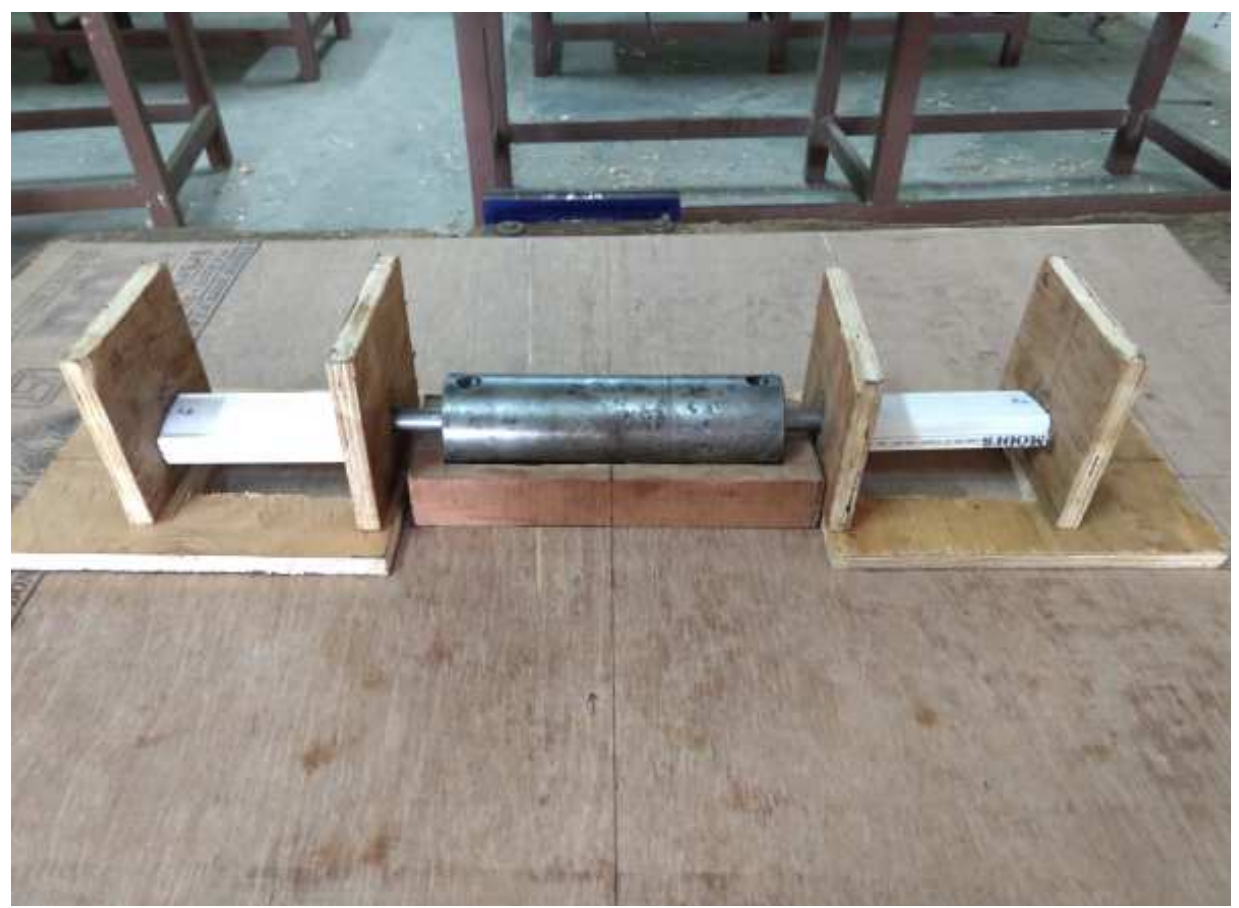

Figure 18: Fixture for the cylinder and coil arrangement. 


\section{CONCLUSIONS}

The Composite Cycle Engine (CCE) is a new and developing engine is a hybrid between a piston and a turbo-fan engine. It uses a piston system instead of a high-pressure compressor which enables the engine to achieve a hectopressure ration which increases efficiency. But the major drawback of this piston system is the increase in weight and to overcome this issue the paper proposes a new type of air compression system which utilizes electromagnetic force instead of mechanical linkage to compress air. The concept utilizes the electromagnetic forces generated by coils to attract and repel the piston through which compression of air takes place. The prototype made based on the concept is similar to a double-acting cylinder which has chambers on both the side of the piston but the piston also has rods extruded from both the side to accommodate the coils over them to provide the electromagnetic force. The paper discusses the detailed design of the cylinder and piston and the various special aspects taken into consideration such as the splitting of the cylinder into two parts to ease in maintenance work, the detailed design of the piston to accommodate the O-rings. After the design of the cylinder and piston was completed it was structurally analyzed. The cylinder was analyzed by simulating internal pressure and the piston analyzed by simulating pressure on the surface of the piston and force acting on the rods axially. The analysis was done for varying pressure and forces to check for safety. The maximum deformation, stress, and strain developed in the cylinder at the desired $0.2 \mathrm{MPa}$ output pressure are 4.47E-06mm, w0.22799 MPa, and 1.19E-06 respectively. The maximum deformation, stress, and strain developed in piston and rods at the desired $0.2 \mathrm{MPa}$ output pressure are $0.00010015 \mathrm{~mm}, 0.17792 \mathrm{MPa}$, and 8.94E-07respectively. After the analysis of the design was completed the prototype was made using EN31 materials the main property while selecting the material was it to be ferrous in nature so that the magnetic effect attracts it. Two solid rods of 60 and $40 \mathrm{~mm}$ were selected to make the cylinder and piston. As mentioned in the design the cylinder was made in two parts and the rods and piston were made from a single rod for structural integrity. Then after the parts were made the pneumatic components, we assembled according to the circuit which is completely manual to simplify the integration with the prototype. The fixtures for the prototype and coils were made on a wooden plank with different fixtures for every component. The next step would be testing the prototype by integrating the coils in the fixture and applying current to them so that the magnetic effect is created and compression takes place.

\section{REFERENCES}

1. Cravey, W. R., Devlin, G. L., Loree, E. L., Strohl, S. T., \& Young, C. hd. (n.d.). DESIGN AND TESTING OF A 25-STAGE ELECTROMAGNETIC COIL GUN Tetra Corporation Albuquerque, NM 87109. Tetra Corporation, 1323-1328.

2. Group, H. L. (n.d.). Flightpath 2050 Europe's Vision for Aviation. https://doi.org/10.2777/50266

3. Kaiser, S., Kellermann, H., Nickl, M., \& Seitz, A. (2018). A COMPOSITE CYCLE ENGINE CONCEPT FOR YEAR 2050, (September).

4. Lee, S., Kim, J. H., \& Kim, S. (2016). 2030. Design and experiments of multi-stage coil gun system, 2053-2060.

5. Nickl, M., V, B. L., Kaiser, S., \& V, B. L. (2017). Aerospace Europe 6th CEAS Conference Evaluation of Piston Engine Modes and Configurations in Composite Cycle Engine Architectures Aerospace Europe 6th CEAS Conference, (867), 1-11.

6. Zhang, Y., Ruan, J., Hu, Y., \& Liu, K. (2012). Driving Circuit Research of a Coil Launcher, (c). 

